\title{
Recent Progress in Preparation and Applications of Oxazino[4,3-a] pyrroloimidazo[5,4-f]benzimidazole (imino)quinone as an Anti-Cancer Agent
}

\author{
Mohammed Yaqob Shareef ${ }^{1,}$, , Noor Mohammed Yaqob Shareef ${ }^{2}$ \\ ${ }^{1}$ Department of Pharmacy, Mazaya University College, A Nasiriyah, Iraq \\ ${ }^{2}$ Department of Pharmacy, School of Life Sciences and Pharmacy and Chemistry, Kingston University, London, United Kingdom
}

Email address:

myshareef62@yahoo.com (M. Y. Shareef)

*Corresponding author

To cite this article:

Mohammed Yaqob Shareef, Noor Mohammed Yaqob Shareef. Recent Progress in Preparation and Applications of Oxazino[4,3-a] pyrroloimidazo[5,4-f]benzimidazole (imino)quinone as an Anti-Cancer Agent. International Journal of Pharmacy and Chemistry. Vol. 7, No. 5, 2021, pp. 85-100. doi: 10.11648/j.ijpc.20210705.12

Received: April 14, 2021; Accepted: August 7, 2021; Published: September 15, 2021

\begin{abstract}
The aim of this study is to prepare a novel precursor for the synthesis of imidazo[5,4f]benzimidazole(imino)quinone. This will target the over-expression of the enzyme $\mathrm{NAD}(\mathrm{P}) \mathrm{H}$ : quinone oxidoreductase (NQO1) in solid tumours. An electron withdrawing group was incorporated into the structure, and the substituted ring size was reduced as this is hypothesised to increase its binding affinity to NQO1. The 2,5-difluoroaniline was acetylated using acetic anhydride to produce N-(2,5-difluorophenyl) acetamide. The latter underwent selective nitration to produce $\mathrm{N}$-(2,5-difluoro- 4nitrophenyl) acetamide followed by oxidation using methane sulfonic acid and hydrogen peroxide to give 1,4-difluoro-2,5dinitrobenzene. The synthesized precursor was achieved by the double nucleophilic aromatic substitution of morpholine and pyrrolidine onto 1,4-difluoro-2,5-dinitrobenzene. The 4-(2,5-dinitro-4-pyrrolid-1-yl) morpholine was successfully synthesized in four synthetic steps. The identity and purity were confirmed using NMR with peaks assigned using proton-fluorine coupling values. Further work is recommended for the developments of this study, additional synthetic steps using the novel precursor need to be carried out to achieve oxazino[4,3-a] pyrroloimidazo[5,4-f] benzimidazole(imino)quinone.
\end{abstract}

Keywords: NAD(P)H: Quinone Oxidoreductase, National Cancer Institute, COMPARE Analysis, Computational Docking, 4-(2,5-dinitro-4-pyrrolid-1-yl) Morpholine, Imidazo[5,4-f]benzimidazole (imino)quinone

\section{Introduction}

According to the World Health Organization, there are 10 million new diagnosed cancer cases per year worldwide and rates are set to double by 2020 [1]. Various risk factors, which when modified, can reduce the likelihood of cancer including the reduction of tobacco use, diet, weight control, and smoking cessation [1]. There are a range of cancer therapies that interact with deoxyribonucleic acid (DNA) such as cyclophosphamide, fluorouracil, cisplatin and mitomycin $\mathrm{C}$ (MMC), however, with many anticancer agents there is a lack of selectivity towards cancerous cells [2].

A solid tumour can be formed via the abnormal proliferation of any cell type in the body and can be benign or malignant [3]. A benign tumour remains in its original location whereas a malignant tumour has the ability to invade surrounding healthy tissue and metastasise to other sites in the body via the lymphatic or circulatory system [3]. Therefore, it is of significance to target cancerous cells via preparing compounds that target the overexpression of $\mathrm{NAD}(\mathrm{P}) \mathrm{H}$ : quinone oxidoreductase (NQO1) in solid tumours.

\subsection{Mitomoycin C (MMC)}

MMC shown in Figure 1 is a chemotherapeutic drug which requires enzymatic bioreduction to exert its biological effects [4]. When reduced, it is converted to a reactive biselectrophilic intermediate which alkylates DNA. It also has other mechanisms of action such as inhibiting ribosomal ribonucleic acid (rRNA), and redox recycling [4]. The presence of a quinone group in MMC acts as a prodrug and 
exerts its activity upon reduction. By acting as an electron acceptor, it reacts with the reductase enzyme, NQO1 thus undergoing bio-reductive activation [5]. The study of MMC is relevant to this project as it possess a quinone group necessary for its activity, which can aid in the understanding of the significance of an iminoquinone group in imidazo[5,4f]benzimidazole iminoquinone as an anticancer agent presented in Figure 1.<smiles>C[C@H]1C2=C(C(=O)C=CC2=O)N2C[C@H]3N[C@H]3[C@]12OC(N)=O</smiles>

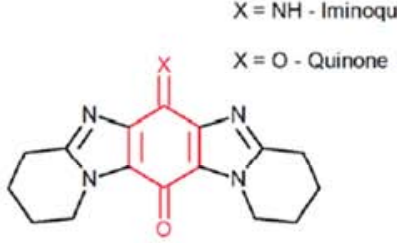

$\mathrm{MMC}$

Imidazo[4,5-f]benzimidazole
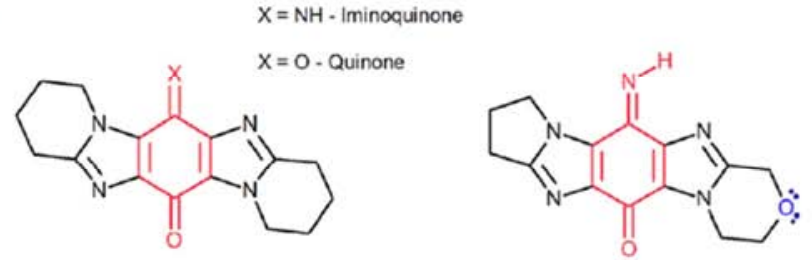

Imidazo[5,4-f]benzimidazole

\section{Novel \\ Imidazo[5,4-f] benzimidazole iminoquinone}

Figure 1. MMC and imidazobenzimidazoles.

\subsection{NAD(P)H: Quinone Oxidoreductase (NQO1)}

NQO1 is a ubiquitous cytosolic flavoenzyme found in numerous human tissues. It is a detoxification enzyme normally expressed in all human cells; however, various types of human cancers have been associated with its elevated expression [6]. A review by Yang et al. in 2014 [7] has demonstrated the presence of over expression of NQO1 in solid tumours such as breast, pancreas, and lungs.

NQO1 is a homodimer with one flavin adenine dinucleotide (FAD) bound to each monomer [8]. This enzyme utilises the reduced pyridine cofactor nicotinamide adenine dinucleotide phosphate $(\mathrm{NAD}(\mathrm{P}) \mathrm{H})$ to catalyse the two-electron reduction of quinones [8]. In addition, it is comprised of 273 amino acids, the major subunit is known as the catalytic domain which is folded into an alpha-beta structure and has residues 1-220. The C-terminal is the second domain, which consists of residues 221-273 and is smaller in size [8].

\subsection{Ping Pong Mechanism}

The ping pong mechanism illustrated in Figure 2, involves $\mathrm{NAD}(\mathrm{P}) \mathrm{H}$ and the quinone substrate binding and reacting then dissociating from the same binding site consecutively. Thus, only one substrate occupies the binding site at any point [9].

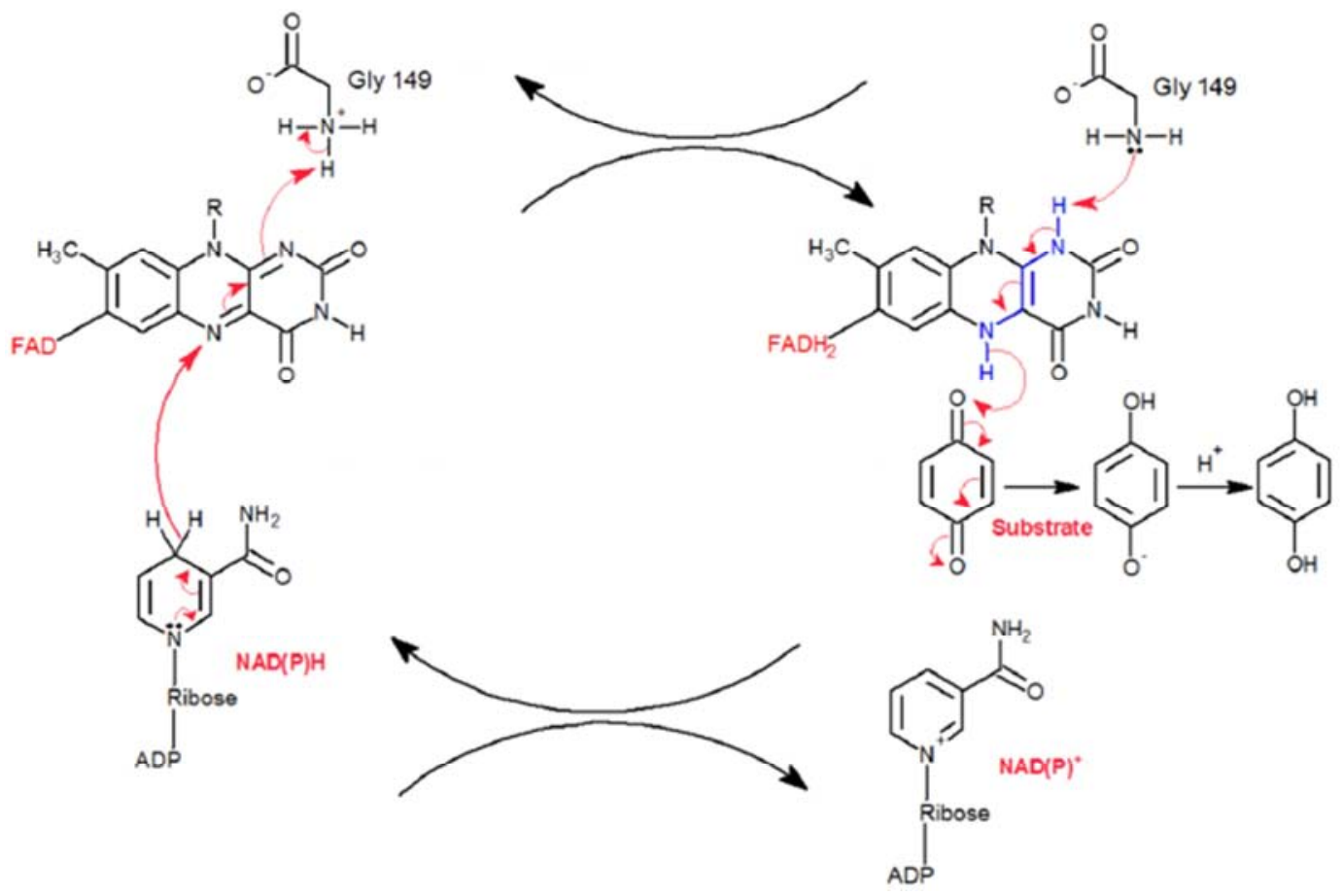

Figure 2. Ping Pong Mechanism Illustration. 
NQO1 possesses a FAD redox factor which during the catalytic cycle stays bound to the NQO1 protein. $\mathrm{NAD}(\mathrm{P}) \mathrm{H}$ reduces FAD to FADH2 resulting in the loss of $\mathrm{NADP}(\mathrm{P})^{+}$ [10]; then reduces the quinone to the toxic hydroquinone in the active site via detoxification, which is then expelled and NQO1 is regenerated [10]. FAD is an essential part in the mechanism of action; it is comprised of an isoalloxazine moiety which interacts in loops with L1 and L4 of one monomer as well as L3 and L5 of the other monomer [9]. The isoalloxazine is anchored via the direct interaction between the aromatic residues Tyr104, Trp105, Phe106, and Leu103 with the rings [9].

The reduction of quinone substrates can be chemoprotective (protects healthy tissue from the side effects) or chemotherapeutic (selectively toxic to the cancerous cell only) depending on the target quinones. The reduction of toxic quinones via NQO1 is achieved via conjugation with glucuronic acid or glutathione and thereby excreted from the cells [6].

\subsection{National Cancer Institute (NCI)}

$\mathrm{NCI}$ is an organization in the United States that facilitates the development of new therapeutic anticancer drugs [11]. The Developmental Therapeutics Program (DTP) is the drug discovery and development division of the NCI which has a database of over 600,000 compounds and 60 cell line screenings [11]. Compounds undergo a 3-cell line, one dose pre-screening to identify compounds with anti-proliferative activity. The active compound then undergoes evaluation against the 60-cell line human tumours over 5 dose ranges [11]. COMPARE is a statistical program used to analyze the responsiveness of each compound against the database of previous agents tested in order to identify similar mechanisms of action [11]. In addition, computational docking is also used to predict the activity of a ligand to its target based on its similarity to a known ligand [12].

\section{Methods \& Materials}

\subsection{Analytical Techniques Used}

In this study Nuclear Magnetic Resonance (NMR), Distortionless enhancement by polarisation transfer (DEPT), and Infrared (IR) analytical techniques were selected to investigate the characteristics of the products. In order to examine the purity of the compounds, melting points (MP) were measured and column chromatography was used as a means of purification.

\subsubsection{Nuclear Magnetic Resonance (NMR)}

NMR spectroscopy is based on the atoms nuclei acting like magnets which become aligned in a magnetic field. The amount of energy is measured that is required to alter the alignment of the nuclei in a magnetic field. Molecules carry a set of energy levels and the transitions between the energy levels are the lines that appear on the spectra. These transitions are produced by a photon of light where frequency is associated with the energy gap between the two levels [13].

\section{(i) Proton Spectra $\left(^{1} \mathrm{H}\right)$}

Proton spectra can be interpreted by observing three factors; integration, chemical shifts and multiplicities of resonance. The spinning particle is the atomic nucleus which is charged and produces a magnetic field. When no external magnetic fields applied, the nuclear spins are in random directions [14]. However, upon the application of an external magnetic field, the nuclei align either with the external magnetic field or against it. Alpha spin state is the term given to protons that are lower in energy state as they align along the external magnetic field. Beta spin states refer to protons with a higher energy level and align against the external magnetic field. The difference in energy between the alpha and beta spin states is referred to as delta E [14]. Therefore, there is a larger energy difference between the alpha and beta spin states when a greater strength of the magnetic field is applied. When an external magnetic field is applied with the same energy as delta E, the spin flips from alpha spin state to beta, allowing the nuclei to undergo relaxation and return to its original state, whilst emitting electromagnetic signals in which the frequencies of these signals depends on delta E. These signals are processed, and a graph is generated of the frequencies against intensity [14].

\section{(ii) Carbon 13 Spectra $\left({ }^{13} \mathrm{C}\right)$}

${ }^{13} \mathrm{CNMR}$ generates peaks each representing a different carbon environment, this is because each one resonates at unique frequencies [13]. The presence of different frequencies is due to the electrons surrounding each nucleus which create an electric current thus creating its own magnetic field. This creates shielding of the nucleus by the electrons from the external magnetic field being applied. Therefore, whenever the distributions of electrons are different from one ${ }^{13} \mathrm{C}$ to another ${ }^{13} \mathrm{C}$ atom, the magnetic field it generates is different as well, hence the varying resonating frequencies [13].

Distortionless Enhancement by Polarisation Transfer (DEPT)

DEPT is used for gaining information on the number of $\mathrm{CH}, \mathrm{CH}_{2}$, and $\mathrm{CH}_{3}$ molecules in the compound as well as the multiplicity of the carbon atoms. DEPT generates spectra where $\mathrm{CH}_{2}$ signals are negative peaks and $\mathrm{CH}$ and $\mathrm{CH}_{3}$ are positive peaks [13].

\subsubsection{Infrared (IR)}

IR spectroscopy is used to obtain structural analysis of a compound. When electromagnetic radiation is introduced, atoms in a compound absorb the energy which changes the state of the atoms within a molecule. This results in changes to the amplitude and frequency of molecular vibrations that gets measured and an IR spectrum is produced [15].

\subsubsection{Chromatography}

Chromatography is a technique used to separate 
different compounds in a mixture. The mixture is applied onto the surface and the fluid phase which is stationary separates the different compounds in the mixture via the aid of the mobile phase. The separation forces can be dictated by the differences in molecular weight of the compounds, partition differences, as well as adsorption with relation to molecular characteristics of the mixed compounds. Therefore, due to these variations, some compounds will move slower in the chromatography system thus remain in the stationary phase for a longer period of time whereas less polar compounds will elute faster in the system [16].

\section{(i) Thin Layer Chromatography (TLC)}

TLC is used to identify if there is a mixture of compounds in a sample. TLC is carried out on a sheet which is normally coated with silica or alumina. The sample is dotted on the lower part of the plate which is then placed inside a glass jar containing the mobile phase. The mobile phase travels upwards through the plate via capillary action, this pushes the sample upwards at different rates as the analytes have different polarity thus creating separation. Less polar compounds elute faster on the TLC plate. The plate is then analyzed under florescence light to identify the position of the separated compounds on the plate [16].

\section{(ii) Column Chromatography}

Column chromatography is used to separate compounds in a mixture. The column is packed with silica and a solvent and the sample is placed gently above it. The solvent that moves the sample down the column is poured into the column, and some compounds will move slower than others as the interaction with the stationary phase is stronger, thus are retained in the column longer. However, less polar analysts interact weakly with the silica, and come out of the column faster [16].

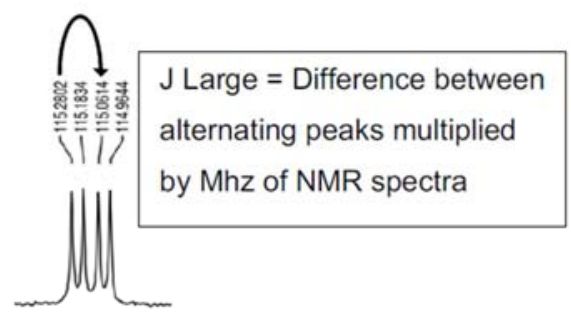

\section{Researched Methodology}

\subsection{Data Analysis and Instrumentation}

\subsubsection{NMR}

${ }^{13} \mathrm{C}-\mathrm{NMR}$ and ${ }^{1} \mathrm{H}-\mathrm{NMR}$ were generated on a Bruker spectrometer at $100.5 \mathrm{MHz}$ and $399.7 \mathrm{MHz}$ respectively. Solvents used include deuterated chloroform $(\mathrm{CDCl} 3)$ and dimethyl sulfoxide (DMSO where the solvent peak was used as an internal standard. The chemical shift values were presented in parts per million (ppm) and the coupling constants $(J)$ were given to four decimal places when required, in the units $\operatorname{Hertz}(\mathrm{Hz})$.

\subsubsection{Melting Points}

Melting points were measured via Sanyo MPD350 GALLENKAMP and compared to references on Reaxys.

\subsubsection{IR}

IR data were obtained using Thermo Scientific NicoletTM iSTM5 FTIR Spectrometer.

\subsection{4. $T L C$}

TLC samples were gathered using aluminum-backed plates with the stationary phase being silica gel Merck Kieselgel 60 F254 and a mobile phase of ethyl acetate in petroleum. In order to detect TLC spots, Uvitec UV lamp was used at $254 \mathrm{~nm}$ wavelength.

\subsection{J Values Calculations}

$J$ values were calculated from the proton NMR spectra in order to find the proton-proton, and proton-fluorine coupling constants. J values were also calculated in ${ }^{13} \mathrm{CNMR}$ where there was carbon-fluorine coupling and reference values are shown in Figure 3. This is calculated by working out the distance between the peaks generated on the spectra where there is more than one splitting. As shown in Figure 3, two values can be calculated, J large and $\mathrm{J}$ small.

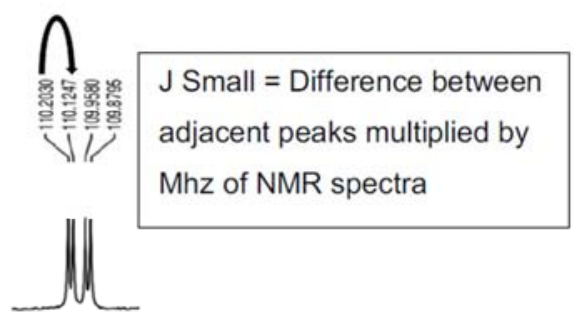

Figure 3. Representation of J Large and J Small calculations.

Carbon-carbon coupling was not observed in the 13CNMR due to the NMR being run using ${ }^{13} \mathrm{C}$, which has very low abundance, thus no coupling between the carbons atoms appear. ${ }^{13} \mathrm{C}$ is an isotope of ${ }^{12} \mathrm{C}$, and contains one extra neutron, giving it a net spin of $1 / 2$. The compounds synthesized throughout the experiment contain fluorine, this couples to both proton and carbon and the reference values are shown in Figures 4 and 5 respectively, therefore coupling was observed in the spectra as it has not been fluorine de-coupled.

When the number of protons is added to the number of neutrons and the value is odd, this means the nucleus has a half integer spin. Both $19 \mathrm{~F}$ and $1 \mathrm{H}$ both have $1 / 2$ nuclei spin therefore are equivalent and couple to each other which appears on the spectra [17]'.

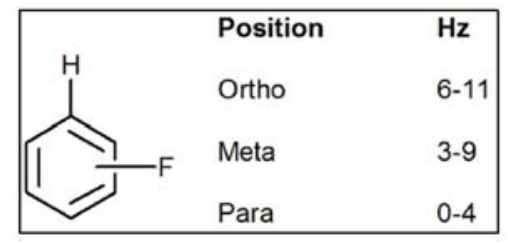

Figure 4. Reference J values for 1HNMR [18]. 


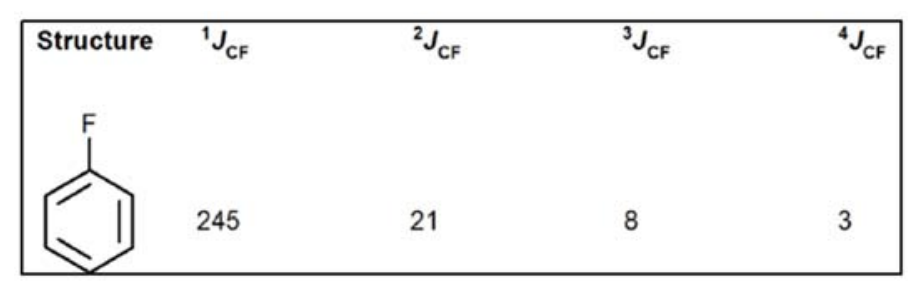

Figure 5. Reference J values for carbon-fluorine coupling [18].

\subsection{Percentage Yield Calculations}

In order to calculate percentage yield, theoretical yield was first calculated via the following equation:

$$
\text { Theoretical yield }=\frac{\text { Millimoles of limiting reagent } \times \text { Molecular Weight of product }}{1000}=g
$$

To calculate percentage yield, the following equation was used:

$$
\text { Percentage yield }=\frac{\text { Theoretical }(g)}{\text { Actual }(g)} \times 100
$$

\subsection{Retention Factor Calculations}

Retention factor $\left(\mathrm{R}_{\mathrm{f}}\right)$ was calculated from the TLC plate after visualization under UV. Analytes that travel farther on the silica plate, have a larger $\mathrm{R}_{\mathrm{f}}$ value, therefore appear less retained on the plate. $R_{\mathrm{f}}$ can be calculated using the following equation:

$$
\mathrm{R}_{\mathrm{f}}=\frac{\text { Distance travelled by compound }}{\text { Distance travelled by solvent }}
$$

\subsection{Experimental Procedure Instrumentation}

Rotatory evaporator BUCHI Rotavapor RII was used to remove any solvent from the sample. Magnetic hotplate stirrer SciQuip Gyrostir 280 was used to stir reaction mixtures and utilized as a source of heat when required. Column chromatography was used to purify and separate the products in the reaction mixture using Merck Kieselgel $60 \mathrm{H}$ Silica gel (70 - 230 mesh) and petroleum ether/ethyl acetate (9:1).

\subsection{Software}

$\mathrm{ACD} / \mathrm{Chem} \mathrm{Sketch}^{\circ}$ was used to draw all structures and mechanisms. To process and analyze NMR spectra Topsin was used. IR spectra were generated and processed via OMNIC software.

\section{Experimental Lab Work}

\subsection{Preparation of N-(2,5-difluorophenyl) Acetamide}

2,5-Difluoroaniline (5.000 g, $38.7 \mathrm{mmol})$ and $\mathrm{Ac}_{2} \mathrm{O}(18.2$ $\mathrm{mL}, 193.7 \mathrm{mmol})$ were refluxed in $\mathrm{MeOH}(129.0 \mathrm{~mL})$ for 30 min. The reaction mixture was cooled and evaporated. Ice water $(500 \mathrm{~mL})$ was added and the mixture was stirred for $1.5 \mathrm{~h}$. The precipitate was collected, washed with distilled water, and dried to give $\mathrm{N}$-(2-5-diflurophenyl) acetamide, product (1) $91 \%$ as shown below; white solid; m. p. 121$123^{\circ} \mathrm{C}$, [19-21] $\left(122.5^{\circ} \mathrm{C}\right) .{ }^{1} \mathrm{HNMR}(399.7 \mathrm{MHz}, \mathrm{CDCl} 3)$ : $\delta=2.23(\mathrm{~s}, 3 \mathrm{H}, \mathrm{Me}), 6.68-6.74(\mathrm{~m}, 1 \mathrm{H}), 6.99-7.05(\mathrm{~m}, 1$
H), 7.62 (s, $1 \mathrm{H}, \mathrm{NH}$, exchanges with D2O), $8.12-8.17$ (m, 1ppm. ${ }^{13} \mathrm{CNMR}(100.5 \mathrm{MHz}, \mathrm{CDCl} 3): \delta=24.6(\mathrm{~s}, \mathrm{Me}), 108.8$ $\left(\mathrm{d},{ }^{2} \mathrm{JCF}=30.0 \mathrm{~Hz}, \mathrm{C}-6\right), 110.0\left(\mathrm{dd},{ }^{2} \mathrm{JCF}=24.6 \mathrm{~Hz},{ }^{3} \mathrm{JCF}=7.9\right.$ $\mathrm{Hz}), 115.1\left(\mathrm{dd},{ }^{2} \mathrm{JCF}=22.0 \mathrm{~Hz},{ }^{3} J \mathrm{CF}=9.7 \mathrm{~Hz}\right), 127.3(\mathrm{t}$, $J C F=12.2 \mathrm{~Hz}, \mathrm{C}-1), 148.2\left(\mathrm{dd},{ }^{2} J \mathrm{CF}=238.4 \mathrm{~Hz},{ }^{3} \mathrm{JCF}=2.8 \mathrm{~Hz}\right.$, $\mathrm{CF}), 158.6\left(\mathrm{dd},{ }^{2} \mathrm{JCF}=241.0 \mathrm{~Hz},{ }^{3} \mathrm{JCF}=2.2 \mathrm{~Hz}, \mathrm{CF}\right), 168.6(\mathrm{~s}$, $\mathrm{C}=\mathrm{O})$. IR (neat): $\tilde{\mathrm{v}}=1018,1040,1095,1140,1194,1239$, 1254, 1326, 1366, $1669(\mathrm{C}=\mathrm{O}), 3264,3264(\mathrm{NH}) \mathrm{cm}^{-1}$.

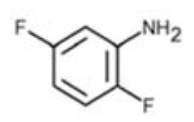

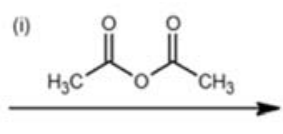

(ii) $\mathrm{MeOH}$, r.t., $30 \mathrm{~min}$

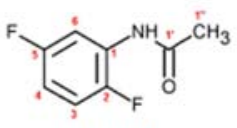

(1) $91 \%$

\subsection{Preparation of $\mathrm{N}$-(2,5-difluoro-4-nitrophenyl) Acetamide}

$N$-(2-5-difluorophenyl) acetamide (4.000 g, $23.4 \mathrm{mmol})$ was gradually stirred in a mixed solution of $\mathrm{H} 2 \mathrm{SO} 4(38.0 \mathrm{~mL})$ and $\mathrm{HNO}_{3}(70 \%, 19.0 \mathrm{~mL})$ at $0^{\circ} \mathrm{C}$. The solution was stirred for 1.5 $\mathrm{h}$, poured onto crushed ice $(500 \mathrm{~g})$ and stirred for $40 \mathrm{~min}$. The precipitate was collected, washed with distilled water, and dried to give $\mathrm{N}$-(2,5-difluoro-4-nitrophenyl) acetamide, product (2) $92 \%$ as shown below; yellow solid; m. p. 188$190^{\circ} \mathrm{C}$, [22-24] (189-190 $\left.{ }^{\circ} \mathrm{C}\right) .{ }^{1} \mathrm{HNMR}(399.7 \mathrm{MHz}, \mathrm{CDCl} 3)$ : $\delta=2.23(\mathrm{~s}, 3 \mathrm{H}, \mathrm{Me}), 7.56(\mathrm{~s}, 1 \mathrm{H}, \mathrm{NH}), 7.84\left(\mathrm{dd},{ }^{3} J C F=10.5\right.$ $\left.\mathrm{Hz},{ }^{3} J C F=6.6 \mathrm{~Hz}, 1 \mathrm{H}, 6 \mathrm{H}\right), 8.47$, (dd, ${ }^{3} J C F 13.0 \mathrm{~Hz},{ }^{3} J C F=6.5$ $\mathrm{Hz}, 1 \mathrm{H} \mathrm{3-H}$ ). ${ }^{1} \mathrm{HNMR}$ (399.7 MHz, DMSO): $\delta=2.19$ (s, $3 \mathrm{H}$, $\mathrm{Me}), 8.17\left(\mathrm{dd},{ }^{3} \mathrm{JCF}=7.1 \mathrm{~Hz},{ }^{3} J C F=10.8 \mathrm{~Hz}, 1 \mathrm{H}, \mathrm{H} 6\right), 8.34$ (dd, $\left.{ }^{3} J C F=6.5 \mathrm{~Hz},{ }^{3} J C F=14.1 \mathrm{~Hz}, 1 \mathrm{H}, \mathrm{H}-3\right), 10.45$ (s, $1 \mathrm{H}$, NH). ${ }^{13} \mathrm{CNMR}(100.5 \mathrm{MHz}, \mathrm{DMSO}): \delta=24.5$ (s, Me), 109.8 (dd, $\left.{ }^{2} J C F=29.2 \mathrm{~Hz},{ }^{4} J C F=2.6 \mathrm{~Hz}, \mathrm{C}-6\right) 113.5\left(\mathrm{~d},{ }^{2} J C F=26.4\right.$ $\mathrm{Hz}, \mathrm{C}-3), 130.5$, (t, $\left.{ }^{3} J C F=8.5 \mathrm{~Hz}, \mathrm{CN}\right), 134.6,\left(\mathrm{t},{ }^{3} J C F=12.6\right.$ $\mathrm{Hz}, \mathrm{CNO} 2), 147.0\left(\mathrm{dd},{ }^{1} J C F=245.7 \mathrm{~Hz},{ }^{4} J C F=2.3 \mathrm{~Hz}, \mathrm{CF}\right)$, $152.3\left(\mathrm{dd},{ }^{l} J C F=256.8 \mathrm{~Hz},{ }^{4} J C F=2.3 \mathrm{~Hz}, \mathrm{CF}\right), 170.7(\mathrm{~s}, \mathrm{C}=\mathrm{O})$. IR (neat): $\tilde{\mathrm{V}}=1005,1040,1072,1192,1215,1260,1292,1335$, 1356, 1379, $1696(\mathrm{C}=\mathrm{O}), 3082,3369(\mathrm{NH}), 3573,1356(\mathrm{NO} 2)$, $1560(\mathrm{NO} 2) \mathrm{cm}^{-1}$.

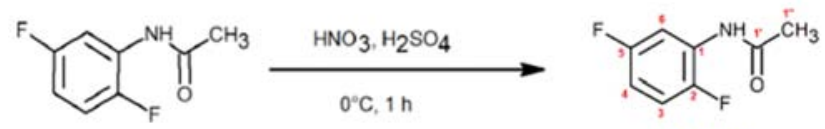

(2) $93 \%$ 


\section{Materials Details}

Table 1. Reagents.

\begin{tabular}{llll}
\hline Reagent & CAS Number & Supplier & Percentage Purity \\
\hline $2,5-$ difluoroaniline & $367-30-6$ & Fisher Scientific & $>98 \%$ \\
Hydrogen Peroxide (50\%) & $7722-84-1$ & Fisher Scientific & - \\
Sulfuric Acid & $7664-93-9$ & Fisher Scientific & - \\
Nitric Acid & $7697-37-2$ & Fisher Scientific & - \\
Methanol & $67-56-1$ & Fisher Scientific & - \\
Acetic Anhydride & $108-24-7$ & Fisher Scientific & $>97 \%$ \\
Morpholine & $110-91-8$ & Fisher Scientific & $\geq 99 \%$ \\
Sodium bicarbonate & $144-55-8$ & Fisher Scientific & - \\
Pyrrolidine & $123-75-1$ & Fisher Scientific & $99 \%$ \\
Silica Powder & $63231-67-4$ & Fisher Scientific & - \\
Petroleum Ether $40-60^{\circ} \mathrm{C}$ & $64742-49-0$ & Fisher Scientific & - \\
Ethyl Acetate & $141-78-6$ & Fisher Scientific & $99 \%$ \\
\hline
\end{tabular}

\section{Results and Discussion}

Synthesis of $\mathrm{N}$-(2,5-difluorophenyl) acetamide using (1.66 g), (1.80 g), (5.00 g)

The first reaction involved the acetylation of 2,5difluoroaniline to produce $\mathrm{N}-(2,5$-difluorophenyl) acetamide. The purpose of this was to protect the $\mathrm{NH}_{2}$ group at the $\mathrm{C} 1$ position for the next step. The equipment was placed in the oven at $120^{\circ} \mathrm{C}$ for 25 minutes to ensure it is dry. The limiting reagent, 2,5-difluoroaniline was refluxed with acetic anhydride and methanol for 30 minutes. The flask was placed in an ice bucket to cool, and the solvent, methanol was evaporated using a rotatory evaporator. The mixture was poured into a beaker with ice and stirred on a magnetic stirrer for three hours. Distilled water was used to get the washings out and into a beaker. The precipitate was collected via Buchner funnel and vacuum filtration to give a white solid. The product of this reaction, N-(2,5-difluorophenyl) acetamide precipitated in ice thus it is insoluble in water. This is because water absorbs acetic anhydride and converts it to acetic acid in the work up as shown in Figure 6, therefore it was essential to dry the equipment required prior to the experiment. Work up is the isolation of the product, therefore, the work up of this reaction resulted in acetic acid and N-(2,5-difluorophenyl) acetamide.

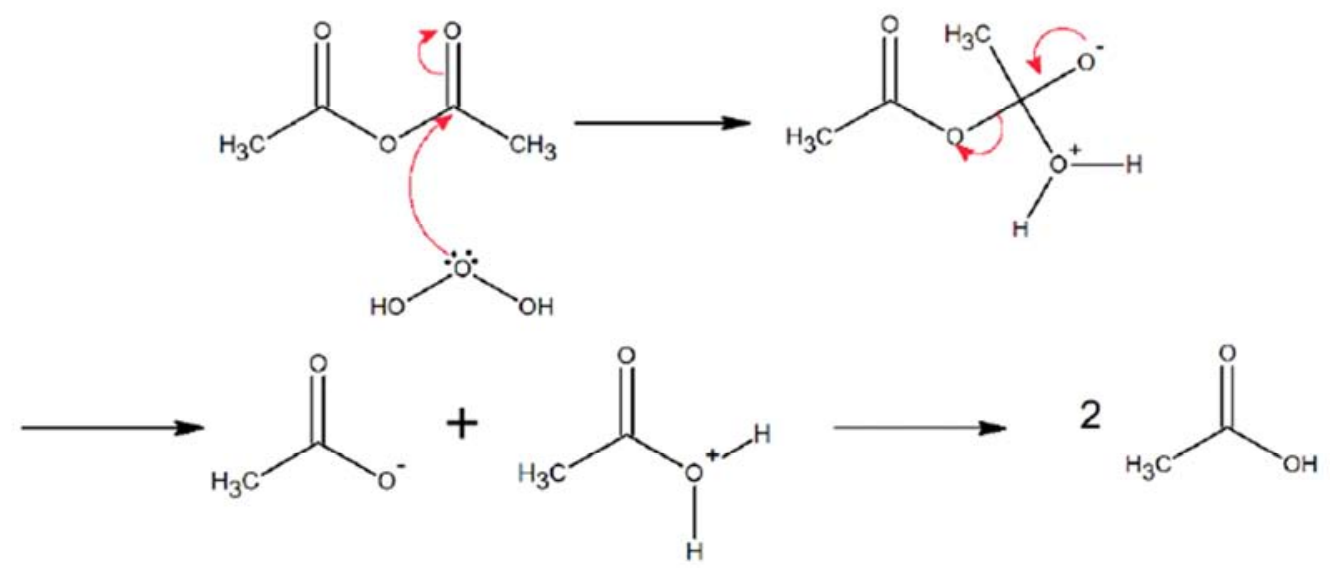

Figure 6. Conversion of acetic anhydride to acetic acid in the presence of water.

Percentage yield was calculated using the method shown in section 2.3 and was found to be $91 \%$. The experiment was repeated three times using different amounts of starting reagent, and the percentage yield was calculated each time as shown in Table 2. The mixture was stirred in ice for longer in experiments 2 and 3, thus allowing more time for the product to precipitate, which may have played a role in the increasing yield.

Table 2. Synthesis of N-(2,5-difluorophenyl) acetamide using varying amounts of starting reagent.

\begin{tabular}{|c|c|c|c|c|}
\hline Experiment no. & Reagent 2,5-difluoroaniline (g) & $\%$ Yield & Precipitation Time (h) & Reflux time (min) \\
\hline 1 & 1.66 & 76 & 1 & 30 \\
\hline 2 & 1.80 & 84 & 1.5 & 30 \\
\hline 3 & 5.00 & 91 & 1.5 & 60 \\
\hline
\end{tabular}


The melting point was measured, and it was found ranging from 121 to $123^{\circ}$ the values well corresponded to the values reported by the study [21]. The melting point helps understand the purity of the compound, as well as if the sample was dry enough. The presence of water in the solid powder would infer a melting point starting around $100^{\circ} \mathrm{C}$ as water evaporates at this temperature.

Characteristic properties of $N$-(2,5-difluorophenyl) acetamide

${ }^{13} \mathrm{CNMR}$ and ${ }^{1} \mathrm{HNMR}$, were used to identify and characterize the product, $N$-(2,5-difluorophenyl) acetamide, as shown in Tables $3 \& 4$ and Figures $7 \& 8$ respectively. NMR was run using deuterated chloroform as the compound showed good solubility in this solvent and the peak is shown at $7.26 \mathrm{ppm}$ in the ${ }^{1} \mathrm{HNMR}$ and $77.2 \mathrm{ppm}$ in the ${ }^{13} \mathrm{CNMR}$. The peak at $2.23 \mathrm{ppm}$ in the ${ }^{1} \mathrm{HNMR}$ was assigned to the methyl group, this is because it is the least electronegative group, and was assigned as the most up field peak. The peaks at 6.68-6.74 ppm and 6.99-7.05 ppm were multiplets corresponding to the protons in the aromatic ring. It is difficult to assign $\mathrm{H} 3$ or $\mathrm{H} 4$ to the peaks because they were multiplets, thus due to the complex nature of the peaks, J values could not be calculated. It can be hypothesized that $\mathrm{H}_{3}$ would be the more downfield peak, as it is four bonds away from the electronegative NH group in the acetamide, whilst $\mathrm{H}_{4}$ is five bonds away, however this cannot be a definitive assignment. The peak at $7.62 \mathrm{ppm}$ was assigned to the $\mathrm{NH}$ group as normally NH peaks are short and broad. The final peak at 8.12-8.17 ppm was assigned to H-6, as shown below, due to the neighboring carbon atoms both attached to electronegative groups, thus would be more downfield.

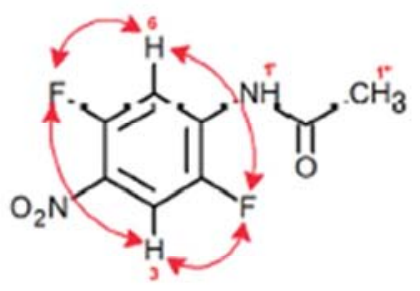

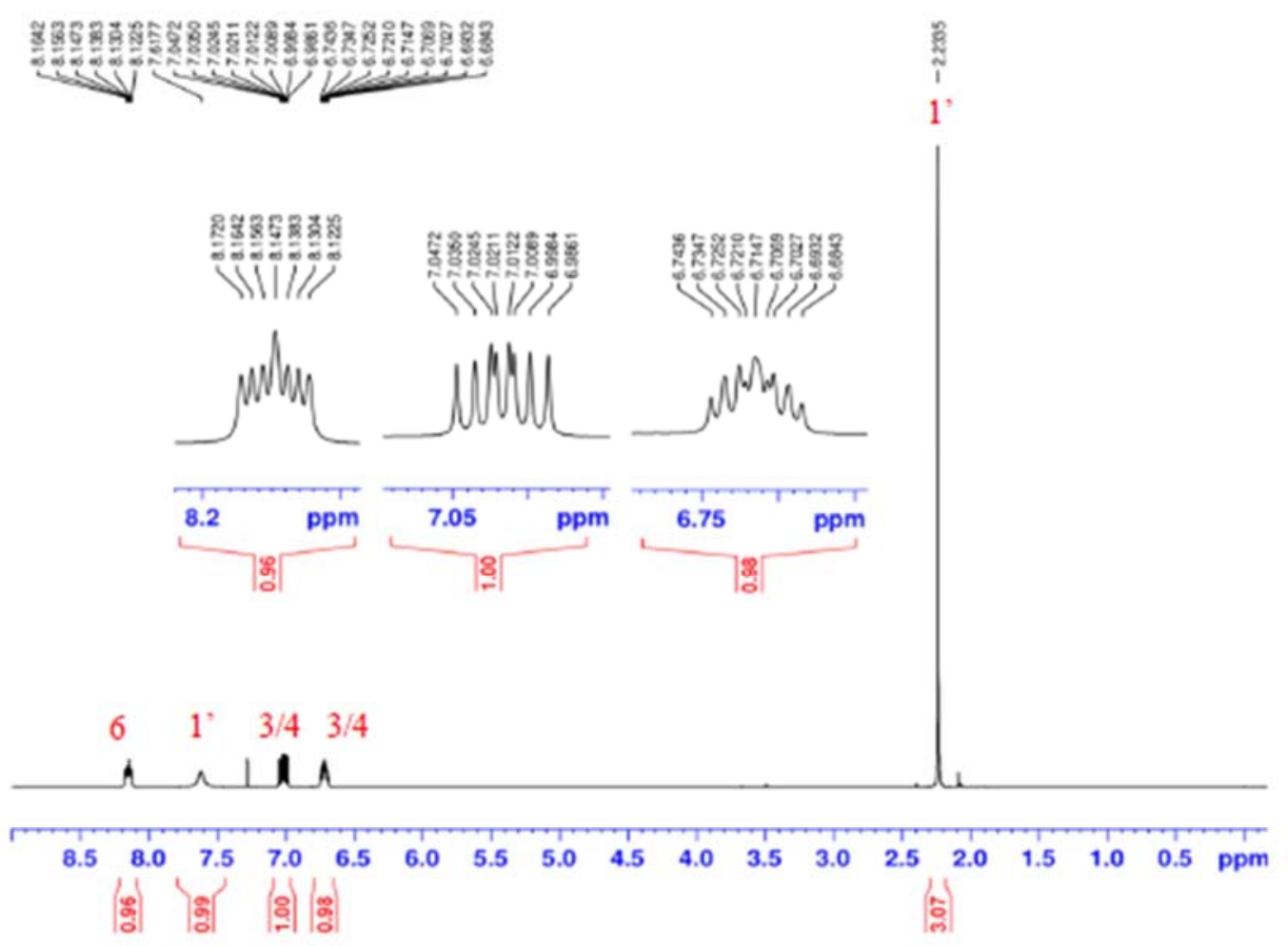

Figure 7. $N$-(2,5-difluorophenyl) acetamide in $C D C l 3$ DEPT and ${ }^{13} C N M R$.

Table 3. $\mathrm{N}$-(2,5-difluorophenyl) acetamide assignment of signals ( $\left.{ }^{\mathrm{H}} \mathrm{HNMR}, 399.7 \mathrm{MHz}, \mathrm{CDCl3}\right)$.

\begin{tabular}{llll}
\hline Chemical Shift (ppm) & Environment & Multiplicity & Assignment \\
\hline 2.23 & $\mathrm{CH} 3$ & $\mathrm{~s}$ & 1 ” \\
$6.68-6.74$ & $\mathrm{CH}$ & $\mathrm{m}$ & $3 / 4$ \\
$6.99-7.05$ & $\mathrm{CH}$ & $\mathrm{m}$ & $3 / 4$ \\
7.62 & $\mathrm{NH}$ & $\mathrm{s}$ & 1, \\
$8.12-8.17$ & $\mathrm{CH}$ & $\mathrm{m}$ & 6 \\
\hline
\end{tabular}


Table 4. $\mathrm{N}$-(2,5-difluorophenyl) acetamide assignment of signals $\left({ }^{13} \mathrm{CNMR}, 100.5 \mathrm{MHz}, \mathrm{CDCl3}\right)$.

\begin{tabular}{llll}
\hline Chemical Shift (ppm) & Environment & Multiplicity & Assignment \\
\hline 24.6 & CH3 & s & 1 " \\
108.8 & CH & d & 6 \\
110.0 & CH & dd & $3 / 4$ \\
115.1 & CH & dd & $3 / 4$ \\
127.3 & CN & t & 1 \\
148.2 & CF & dd & $2 / 5$ \\
158.6 & CF & dd & $2 / 5$ \\
168.6 & CO & s & 1, \\
\hline
\end{tabular}<smiles>[CH2-]C(=O)Nc1cc(F)ccc1F</smiles>

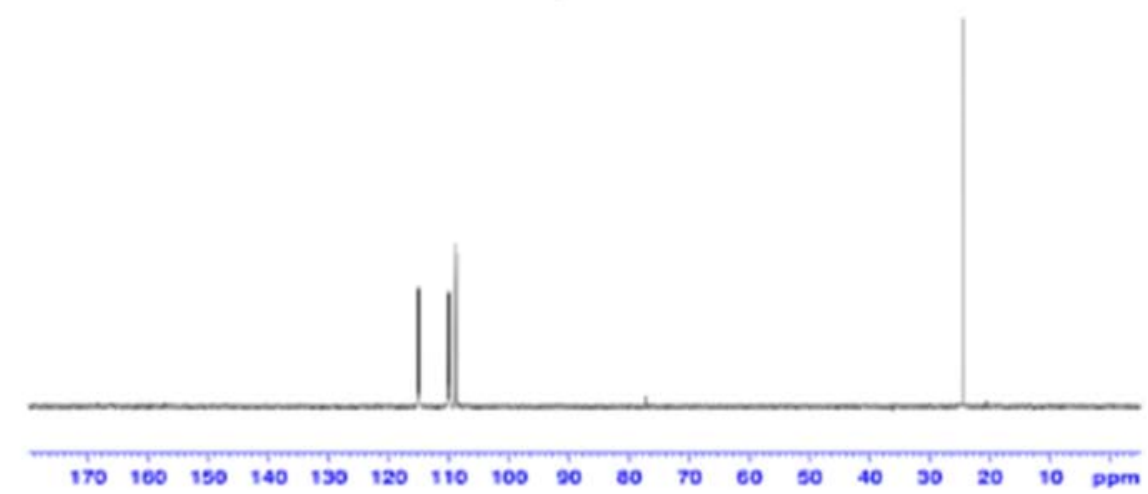

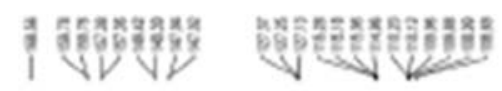

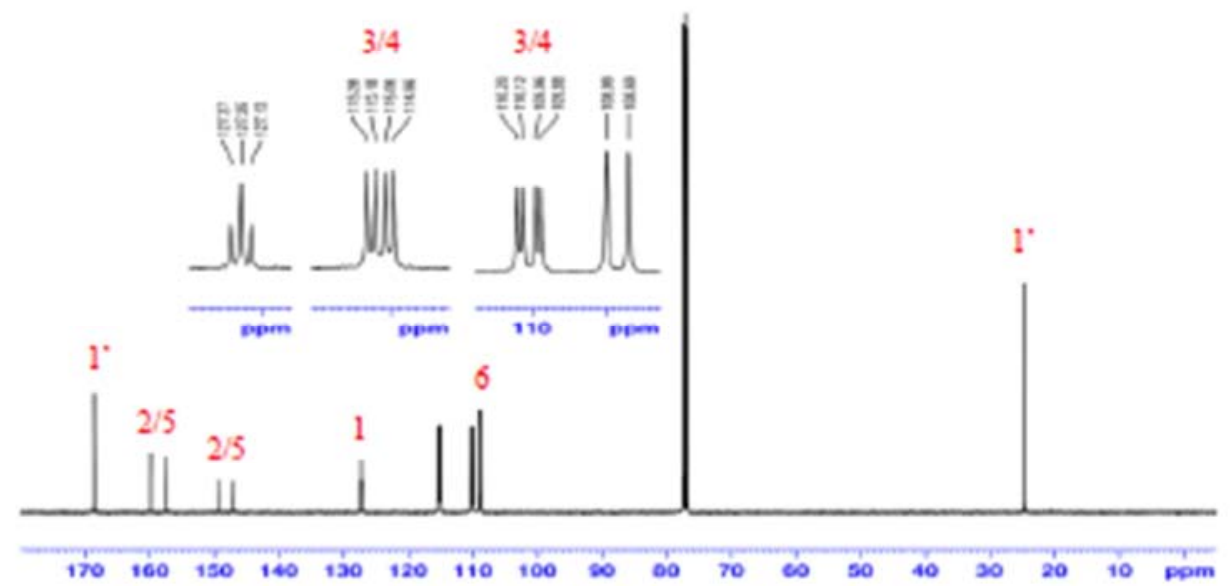

Figure 8. $N$-(2,5-difluorophenyl) acetamide in $C D C l 3{ }^{l} H N M R$.

The furthest peak downfield in the ${ }^{13} \mathrm{CNMR}$ was assigned to the carbonyl group as it is the most electronegative group in the structure. The next two peaks were doublets of doublets, which were assigned to the two CF in the structure. This is because when $\mathrm{J}$ large and $\mathrm{J}$ small were calculated as shown in Table 5, the values corresponded to the carbon being one bond and four bonds away from the other $\mathrm{CF}$ respectively. This means both $\mathrm{C}-\mathrm{F}$ were coupling to each other, thus creating the doublet of doublets shown in the spectra. The two values for $\mathrm{J}$ large were calculated to be $241.0 \mathrm{~Hz}$ and $238.4 \mathrm{~Hz}$, whereas Williams, D., et al. [18] stated a value of $245.0 \mathrm{~Hz}$ for a carbon directly attached to a fluorine. For $\mathrm{J}$ small, the values were $2.2 \mathrm{~Hz}$ and $2.8 \mathrm{~Hz}$, which are close to the $\mathrm{J}$ values reported by other investigators [18]. These finding are supporting the assignment of these peaks to C-F.

The next peak at $127.3 \mathrm{ppm}$ was assigned to the $\mathrm{CN}$ group. This is because when DEPT was run, this peak didn't appear 
on the spectra. DEPT showed all the $\mathrm{CH}$ and $\mathrm{CH}_{3}$ groups however no peak was present in the $\mathrm{CN}$ region confirming there is no hydrogen attached to that carbon, thus was assigned to $\mathrm{CN}$. In addition, $\mathrm{CN}$ was the most electronegative group in comparison to C-3, C-4 and C-6 which were still to be assigned, therefore had to be more downfield. The furthest peak up field was assigned to the $\mathrm{CH}_{3}$ group as it is the least electronegative carbon. The peak at $108.8 \mathrm{ppm}$ was assigned to C-6. This is because when J large was calculated, it was found $30 \mathrm{~Hz}$, whereas Williams, D., et al. [18], reported that if a carbon is 2 bonds away from fluorine, the $\mathrm{J}$ value would be $21 \mathrm{~Hz}$. This value was relatively close to our finding, and hence is supporting the assignment of these peaks. The peaks at $110.0 \mathrm{ppm}$ and $115.1 \mathrm{ppm}$ were both doublets of doublets and both could either be C-3 or C-4. Both C-3 and C-4, as shown below, are two bonds away from the closest fluorine and three bonds away from the furthest fluorine. The $\mathrm{J}$ values calculated were very similar to each other; therefore these two peaks could not be differentiated.

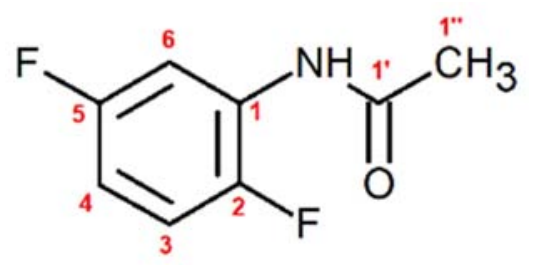

Table 5. $\mathrm{N}$-(2,5-difluorophenyl) acetamide in $\mathrm{CDCl} 3{ }^{13} \mathrm{CNMR} J$ values and assignment.

\begin{tabular}{lll}
\hline J Values & Calculated $(\mathrm{Hz})$ & Assignment \\
\hline${ }^{1} \mathrm{JCF}$ & 241.0 & $\mathrm{C} 2, \mathrm{C} 5$ \\
& 238.4 & $\mathrm{C} 2, \mathrm{C} 5$ \\
${ }^{2} \mathrm{JCF}$ & 30.0 & $\mathrm{C} 6$ \\
& 24.6 & $\mathrm{C} 3 / \mathrm{C} 4$ \\
& 22.0 & $\mathrm{C} 3 / \mathrm{C} 4$ \\
${ }^{3} \mathrm{JCF}$ & 7.9 & $\mathrm{C} 3 / \mathrm{C} 4$ \\
& 9.7 & $\mathrm{C} 3 / \mathrm{C} 4$ \\
& 12.2 & $\mathrm{C} 1$ \\
${ }^{4} \mathrm{JCF}$ & 2.2 & $\mathrm{C} 2, \mathrm{C} 5$ \\
& 2.8 & $\mathrm{C} 2, \mathrm{C} 5$ \\
\hline
\end{tabular}

Synthesis of N-(2,5-difluoro-4-nitrophenyl) acetamide using (2.50

\section{g), $(4.00 \mathrm{~g})$}

Sulfuric acid and nitric acid were stirred at $0^{\circ} \mathrm{C}$ and added dropwise to N-(2,5-difluorophenyl) acetamide. The solution was stirred for 1 hour and poured onto ice to collect the precipitate. This is also to dilute the acid and quench the reaction as it is exothermic. Ice and distilled water were used to get the washings, and the solution was stirred for 40 minutes using a magnetic stirrer. The mixture was then filtered and dried using Buchner funnel and vacuum filtration to give the product, $\mathrm{N}$-(2,5-difluoro-4-nitrophenyl) acetamide, yellow solid. When nitric acid was added dropwise to sulfuric acid in a round bottom flask at $0^{\circ} \mathrm{C}$, fumes being released were observed and the flask became warmer. This was an indication that the electrophile nitronium ion was being generated as shown in Figure 9 via the protonation of the nitric acid.

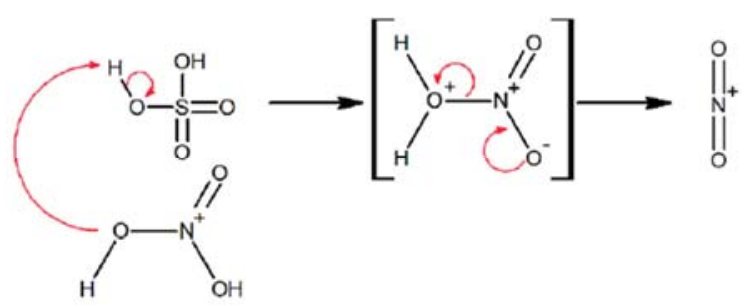

Figure 9. Generation of nitronium ion.

The nitro group selectively attaches at the $\mathrm{C} 4$ position by electrophilic aromatic substitution as illustrated in Figure 10. The presence of steric hindrance at the $\mathrm{C} 4$ carbon is created by the bulky group present at the opposite carbon, $\mathrm{C} 1$. As well as that, the activation by fluorine at $\mathrm{C} 5$ plays a role for the nitronium ion attacking at the $\mathrm{C} 4$ position. The reaction occurs at $0^{\circ} \mathrm{C}$ because it is an activated system due to the fluorine pushing electrons into the system.

Normally, fluorine is very electronegative as it withdraws electrons through the sigma bonds while resonance utilizes pi bonds. Sigma bonds form the skeleton, whilst pi bonds are easier to break, this is known as $+\mathrm{R}$ (resonance) effect which is stronger than $-\mathrm{I}$ (induction) and thus occurs at $0^{\circ} \mathrm{C}$.<smiles>CC(=O)Nc1cc(F)c([N+](=O)[O-])cc1F</smiles>

Figure 10. Nitration of $N-(2,5$-difluorophenyl) acetamide.

Percentage yield was calculated using the method shown in section 2.3 and was found to be $93 \%$. The experiment was repeated twice using different amounts of starting reagent, and the percentage yield is shown in Table 6.

Table 6. Synthesis of N-(2,5-difluoro-4-nitrophenyl) acetamide using varying amounts of starting reagent.

\begin{tabular}{lllll}
\hline Experiment no. & Reagent (g) & \% Yield & Reaction stirring time (h) & Precipitation in ice (min) \\
\hline 1 & 2.50 & 83 & 1 & 30 \\
2 & 4.00 & 87 & 1.5 & 40 \\
3 & 2.50 & 93 & 2 & 50 \\
\hline
\end{tabular}


The melting point was investigated, and its value was found ranging between 188 to $190^{\circ} \mathrm{C}$, which is well corresponding with the values reported by Finger et al. [22]. The melting point didn't start early, that means the compound was dried well and hence no water present in it.

Characteristic properties of N-(2,5-difluoro-4-nitrophenyl) acetamide

${ }^{1} \mathrm{HNMR}$ was carried out using $5 \mathrm{mg}$ and $50 \mathrm{mg}$ of the sample dissolved in $6.5 \mathrm{~mL}$ of deuterated chloroform, however poor solubility of the compound was observed, thus resulting in very identical NMR spectra. The solvent peak at $7.26 \mathrm{ppm}$ appeared very large; therefore the compound had not been dissolved completely. ${ }^{1}$ HNMR was analyzed and the peaks were assigned to the protons in the structure. The furthest peak downfield at $8.47 \mathrm{ppm}$ was a doublet of doublet and was assigned to the proton $\mathrm{H} 3$ as it is attached to the carbon closest to the electronegative $\mathrm{NO}_{2}$ and fluorine. The doublet of doublet was due to the proton coupling to both fluorine atoms. A doublet of doublet was also seen at 7.84 ppm which was assigned to H6 coupling to both fluorine atoms. The peak at $2.23 \mathrm{ppm}$ was assigned to the methyl group being the least electronegative.

$\mathrm{J}$ values were calculated as described in section 2.2 and are shown in Figure 11 and Tables $7 \& 8$. The $J$ values for the protons in the ortho position with respect to the two fluorine elements were calculated to be 10.5 and $13.0 \mathrm{~Hz}$. Williams, D., et al. [18], suggested J values between 6-11 Hz. One of the values was slightly out of range, this could be due to the benzene ring having other substituents, thus affecting the coupling strength between the proton and fluorine. According to Williams, D., et al. [18], a proton in meta position in relation to the fluorine would have a $\mathrm{J}$ value of $3-9 \mathrm{~Hz}$. The calculated values were $6.6 \mathrm{~Hz}$ and $6.5 \mathrm{~Hz}$, which fall within the specified range. This confirms the assignment of the H3 and $\mathrm{H} 6$ protons.

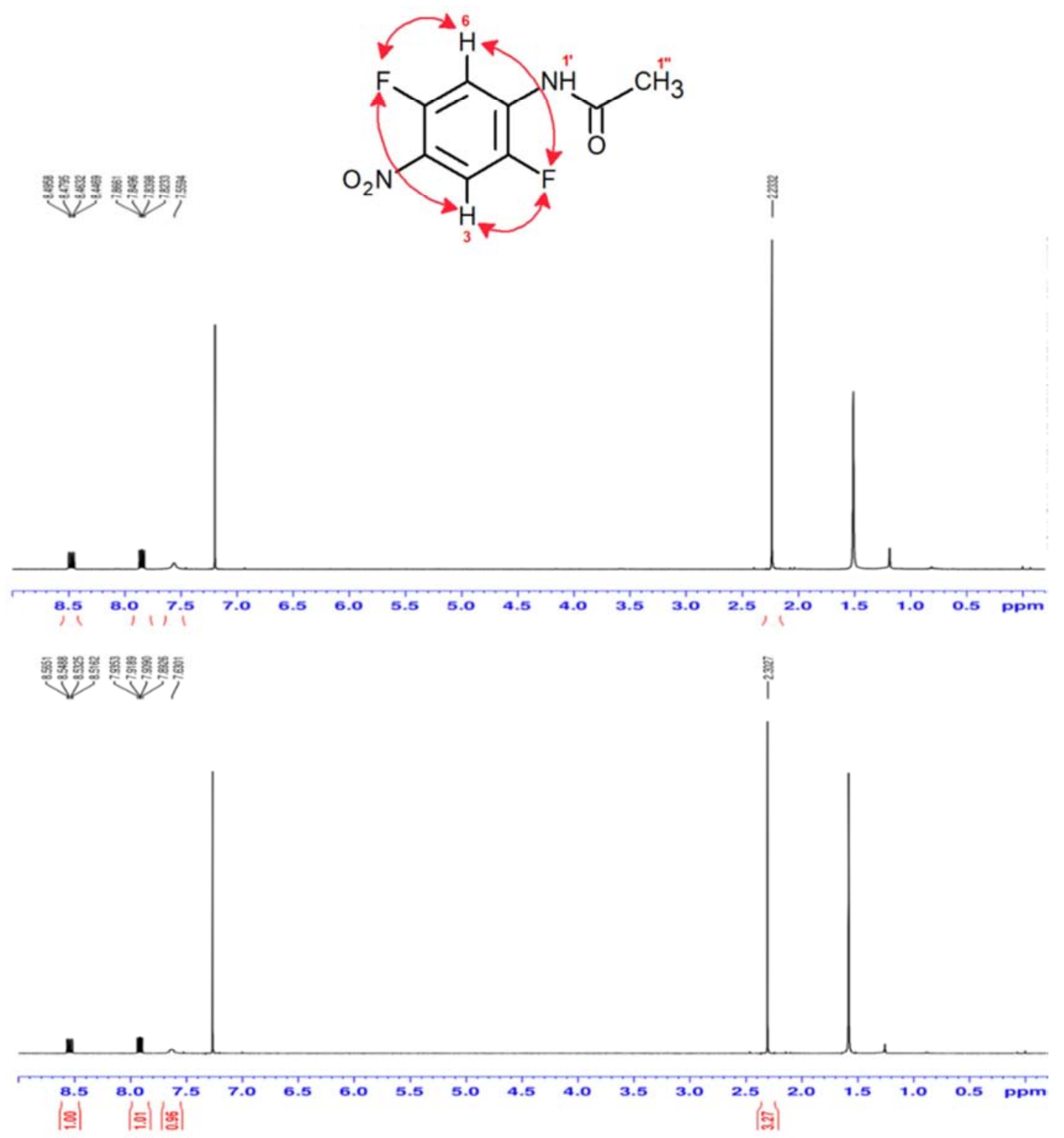

Figure 11. $\mathrm{N}$-(2,5-difluoro-4-nitrophenyl) acetamide, $5 \mathrm{mg}$ and $50 \mathrm{mg}$ in $C D C l 3^{\mathrm{l}} \mathrm{HNMR}$. 
Table 7. N-(2,5-difluoro-4-nitrophenyl)acetamide in $\mathrm{CDCl}_{3} J$ values and assignment.

\begin{tabular}{ll}
\hline Location & Calculated $(\mathbf{H z})$ \\
\hline \multirow{2}{*}{ Ortho } & 10.5 \\
& 13.0 \\
Meta & 6.6 \\
\end{tabular}

Table 8. N-(2,5-difluoro-4-nitrophenyl)acetamide assignment of signals $\left.{ }^{1} \mathrm{HNMR}, 399.7 \mathrm{MHz}, \mathrm{CDCl}\right)$.

\begin{tabular}{llll}
\hline Chemical Shift (ppm) & Environment & Multiplicity & Assignment \\
\hline 2.23 & $3 \mathrm{H}$ & $\mathrm{s}$ & 1 ” \\
7.56 & $\mathrm{NH}$ & $\mathrm{s}$ & 1 \\
7.84 & $\mathrm{H}$ & $\mathrm{dd}$ & 6 \\
8.47 & $\mathrm{H}$ & $\mathrm{dd}$ & 3 \\
\hline
\end{tabular}

Deuterium Oxide $\left(\mathrm{D}_{2} \mathrm{O}\right)$ shake was used to identify protons not attached to a carbon, such as the proton attached to the nitrogen in $N$-(2,5-difluoro-4-nitrophenyl) acetamide. The ${ }^{1}$ HNMR spectra and its corresponding data are presented in Figure 12 and Tables $9 \& 10$ respectively. One drop of $\mathrm{D}_{2} \mathrm{O}$ was added to the sample and NMR was run. The proton exchanged with deuterium, thus the peak appeared smaller as shown in Figure 13 supporting that peak assignment is $\mathrm{NH}$.

The compound was re-run using a different solvent, dimethyl sulfoxide (DMSO). This solvent was chosen as it is polar thus dissolves polar compounds. When dissolving the sample in DMSO, good solubility was observed. The peak at $2.19 \mathrm{ppm}$ was a singlet with an integration value of 3 , thus was assigned to the methyl group, as it is the least electronegative group. The peaks at $8.17 \mathrm{ppm}$ and $8.34 \mathrm{ppm}$ were a doublet of doublets and were assigned to the aromatic protons. Both protons are ortho and para to the two fluorine atoms in the structure therefore couple to both fluorine atoms. The proton at $\mathrm{H} 3$ was assigned to the peak at $8.34 \mathrm{ppm}$, and H6 was assigned to the peak at $8.17 \mathrm{ppm}$, due to $\mathrm{H} 3$ being more electronegative as discussed before. The peak at 8.17 ppm had a $\mathrm{J}$ value of $10.8 \mathrm{~Hz}$ for the hydrogen-fluorine coupling at the ortho position, and $7.1 \mathrm{~Hz}$ for the coupling at the meta position. Both of these values are within the range reported by other investigators [18]. The peak at $8.34 \mathrm{ppm}$ had $\mathrm{J}$ values of $14.1 \mathrm{~Hz}$, and $6.5 \mathrm{~Hz}$ for proton-fluorine coupling at ortho and para positions respectively, which are close to the reference range. The protons at positions 1' and 1 " were assigned as discussed earlier.

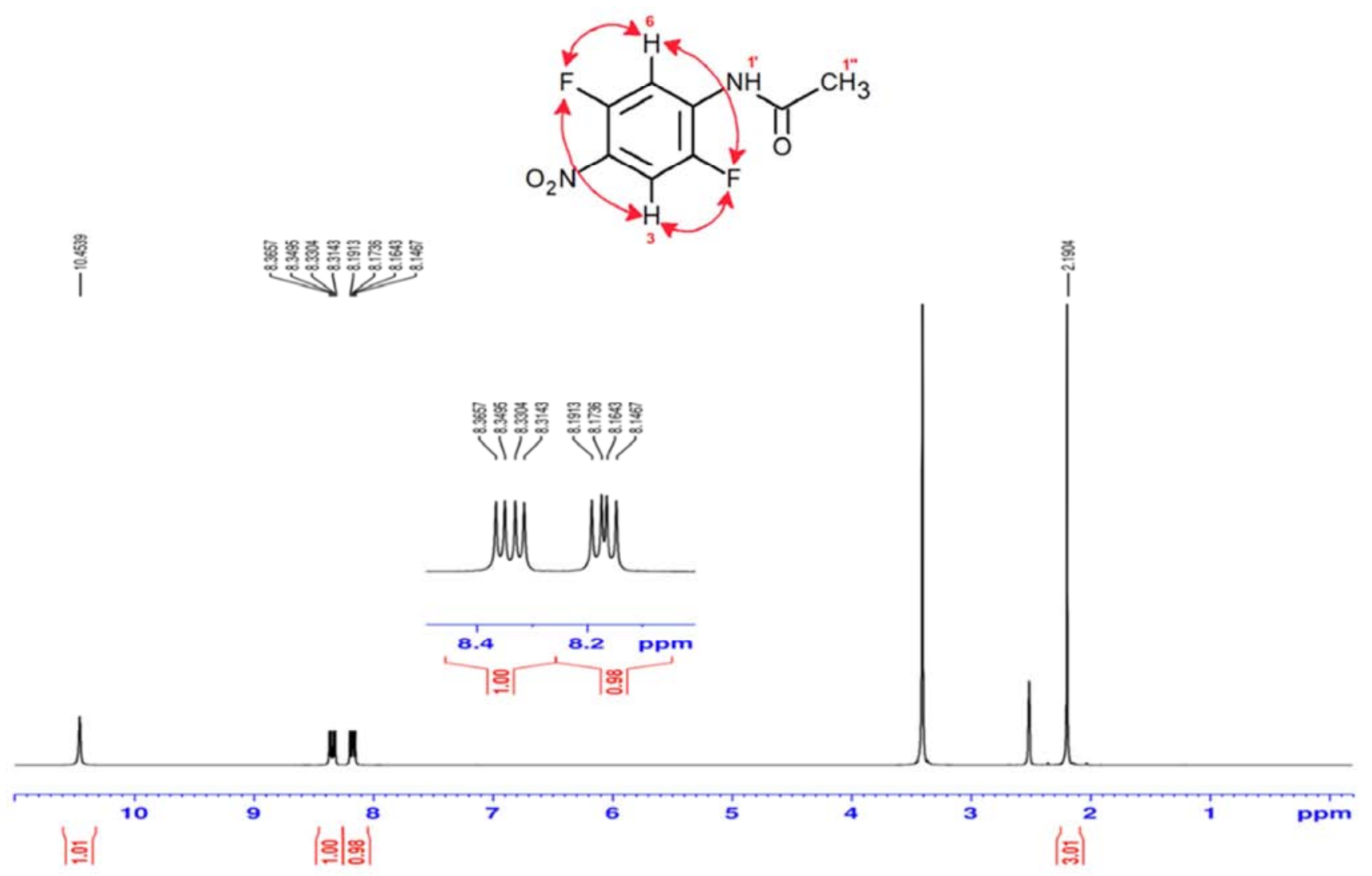

Figure 12. $N$-(2,5-difluoro-4-nitrophenyl) acetamide in DMSO ${ }^{l} H N M R$. 
Table 9. $\mathrm{N}$-(2,5-difluoro-4-nitrophenyl) acetamide assignment of signals (1HNMR, 399.7 MHz, DMSO).

\begin{tabular}{llll}
\hline Chemical Shift (ppm) & Environment & Multiplicity & Assignment \\
\hline 2.19 & $3 \mathrm{H}$ & $\mathrm{s}$ & 1 \\
8.17 & $\mathrm{H}$ & $\mathrm{dd}$ & 1 \\
8.34 & $\mathrm{H}$ & $\mathrm{dd}$ & 6 \\
10.45 & $\mathrm{H}$ & $\mathrm{s}$ & 3 \\
\hline
\end{tabular}

Table 10. N-(2,5-difluoro-4-nitrophenyl) acetamide in DMSO J values and assignment.

\begin{tabular}{ll}
\hline Location & Calculated $(\mathbf{H z})$ \\
\hline \multirow{2}{*}{ Ortho } & 10.8 \\
& 14.1 \\
Meta & 7.1 \\
\end{tabular}

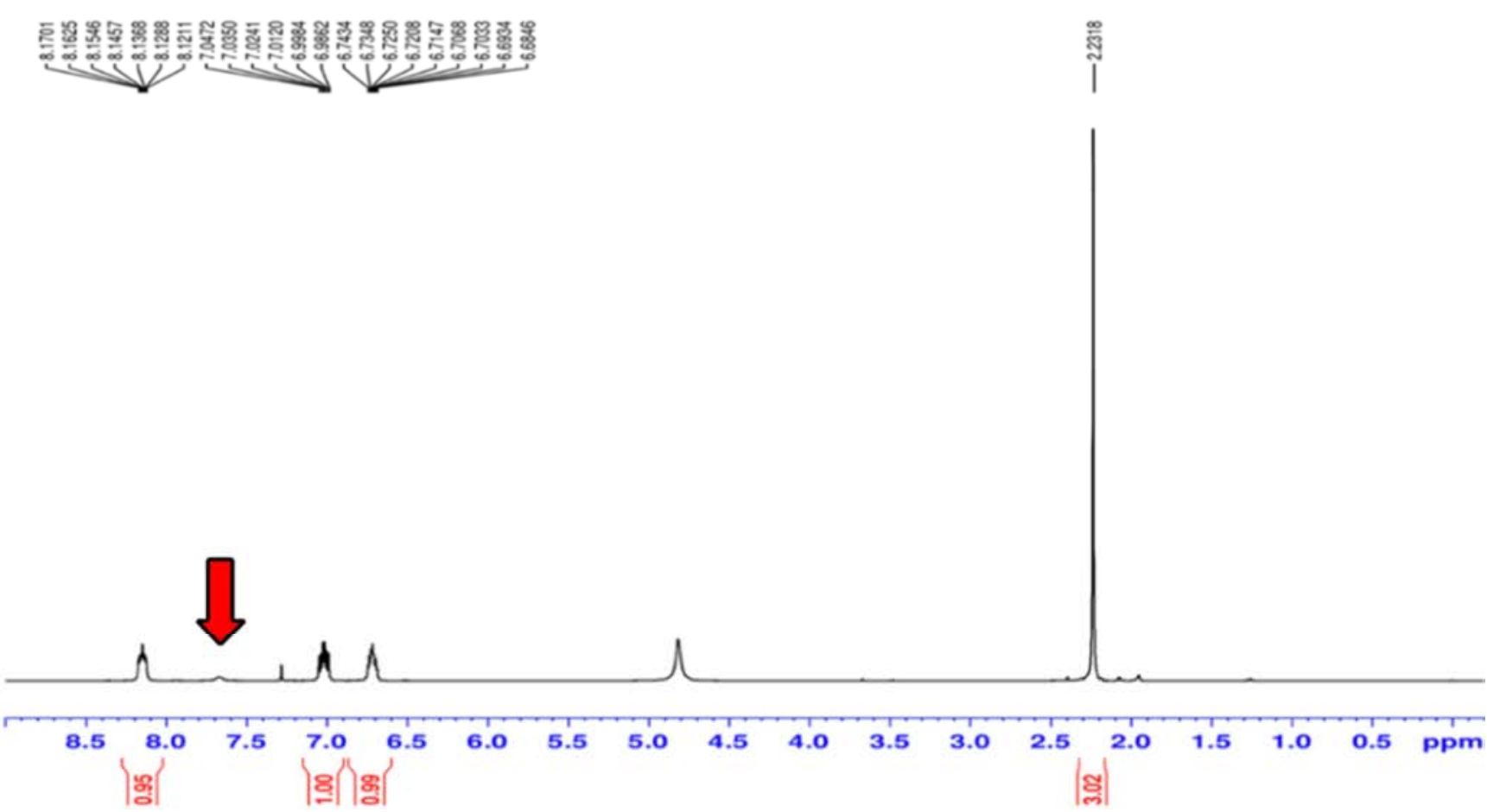

Figure 13. $\mathrm{N}$-(2,5-difluoro-4-nitrophenyl)acetamide ${ }^{l} \mathrm{HNMR} \mathrm{D}_{2} \mathrm{O}$ shake.

The peak at $170.7 \mathrm{ppm}$ in the 13CNMR, as shown in Figure 14 was assigned to the carbonyl group as this is the most electronegative carbon thus furthest downfield on the spectra. The peaks at $152.3 \mathrm{ppm}$ and $147.0 \mathrm{ppm}$ were doublet of doublets and were assigned to the C-F groups. Doublet of doublets appeared as both carbon-fluorine groups were coupling to each other. J large and J small were calculated (Tables $11 \& 12$ ) for the peak at $152.3 \mathrm{ppm}$ and were 256.8 $\mathrm{Hz}$ and $2.3 \mathrm{~Hz}$ respectively. These values are very close to the range stated by Williams, D., et al. [18], which is confirmed the coupling. The peak at $147.0 \mathrm{ppm}$ had a $1 \mathrm{~J}$ large value of $245.7 \mathrm{~Hz}$ and $4 \mathrm{~J}$ small value of $2.3 \mathrm{~Hz}$. These values are within the range and prove the fluorine coupling to both carbon atoms at C-2 and C-5. The next peak was a triplet at $134.6 \mathrm{ppm}$ and was assigned to the $\mathrm{CNO}_{2}$ group. The calculated $3 \mathrm{~J}$ value was $12 \mathrm{~Hz}$, which is agree with the value reported in the literatures [18] for a carbon that is three bonds away from a fluorine as well as being the next most electronegative group supported this assignment. The following peak at $130.5 \mathrm{ppm}$ was also a triplet and the calculated $\mathrm{J}$ value was $8.5 \mathrm{~Hz}$ which is very close to the reference value of $8 \mathrm{~Hz}$. This was assigned to the $\mathrm{CN}$ group. The next peak at $113.5 \mathrm{ppm}$ was assigned to $\mathrm{C} 3$ and the $\mathrm{J}$ value was calculated to be $24.4 \mathrm{~Hz}$. This suggests this carbon is coupling to the fluorine three bonds away, as the calculated $\mathrm{J}$ value is close to the value reported in the literatures [18]. The doublet of doublet at $109.8 \mathrm{ppm}$ was assigned to C-6. The calculated J large value was $29.2 \mathrm{~Hz}$ and $\mathrm{J}$ small was 2.6 Hz. This suggests this carbon coupled to the two fluorine atoms, thus creating the doublet of doublet. The final peak at $24.5 \mathrm{ppm}$ was a singlet and assigned to the methyl group as this is the least electronegative group.

The peaks assigned to $\mathrm{CO}, \mathrm{C}-\mathrm{F}, \mathrm{CNO}_{2}$ and $\mathrm{CN}$ do not appear on the DEPT spectra, therefore these carbon atoms are not attached to a proton. 

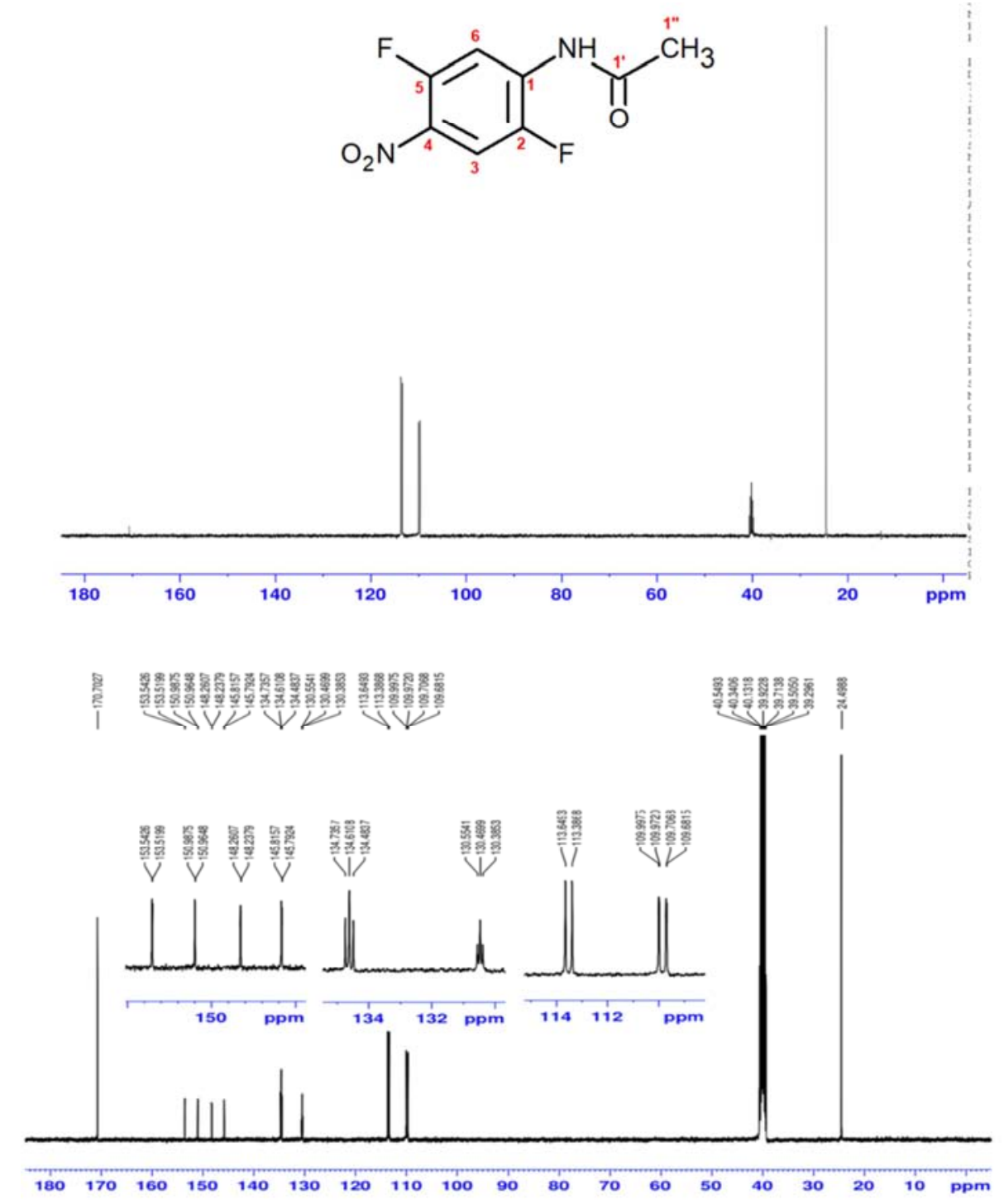

Figure 14. $N$-(2,5-difluoro-4-nitrophenyl) acetamide in DMSO ${ }^{13} C N M R$.

Table 11. $\mathrm{N}$-(2,5-difluoro-4-nitrophenyl) acetamide in DMSO ${ }^{13} \mathrm{CNMR} J$ values and assignment

\begin{tabular}{lll}
\hline J Values & Calculated (Hz) & Assignment \\
\hline${ }^{1} \mathrm{~J}_{\mathrm{CF}}$ & 256.8 & $\mathrm{C} 2 / \mathrm{C} 5$ \\
& 245.7 & $\mathrm{C} 2 / \mathrm{C} 5$ \\
${ }^{2} \mathrm{~J}_{\mathrm{FC}}$ & 29.2 & $\mathrm{C} 6$ \\
& 26.4 & $\mathrm{C} 3$ \\
${ }^{3} \mathrm{~J}_{\mathrm{FC}}$ & 8.5 & $\mathrm{C} 1$ \\
& 12.6 & $\mathrm{C} 4$ \\
${ }^{4} \mathrm{~J}_{\mathrm{CF}}$ & 2.6 & $\mathrm{C} 6$ \\
& 2.3 & $\mathrm{C} 2 / \mathrm{C} 5$ \\
& 2.3 & $\mathrm{C} 2 / \mathrm{C} 5$ \\
\hline
\end{tabular}

Table 12. N-(2,5-difluoro-4-nitrophenyl) acetamide assignment of signals (13CNMR, 100.5 MHz, DMSO).

\begin{tabular}{llll}
\hline Chemical Shift (ppm) & Environment & Multiplicity & Assignment \\
\hline 24.5 & $\mathrm{CH} 3$ & $\mathrm{~s}$ & 1 " \\
109.8 & $\mathrm{CH}$ & $\mathrm{dd}$ & 6 \\
113.5 & $\mathrm{CH}$ & $\mathrm{d}$ & 3 \\
130.5 & $\mathrm{CN}$ & $\mathrm{t}$ & 1 \\
134.6 & $\mathrm{CNO} 2$ & $\mathrm{t}$ & 4 \\
147.0 & $\mathrm{CF}$ & $\mathrm{dd}$ & $2 / 5$ \\
152.3 & $\mathrm{CF}$ & $\mathrm{dd}$ & $2 / 5$ \\
170.7 & $\mathrm{CO}$ & $\mathrm{s}$ & 1, \\
\hline
\end{tabular}


IR Spectra of the Synthesized Compounds

All the synthesized compounds were examined using IR, and their spectra are presented in Figures $15 \& 16$, which are all presented the characterization properties of the features for the synthesized compounds. Table 13 shows all the data obtained from the synthesized compounds, whereas, Table 14 was used as a reference to locate the functional groups in the spectra of the characterized peaks of the synthesized compounds.

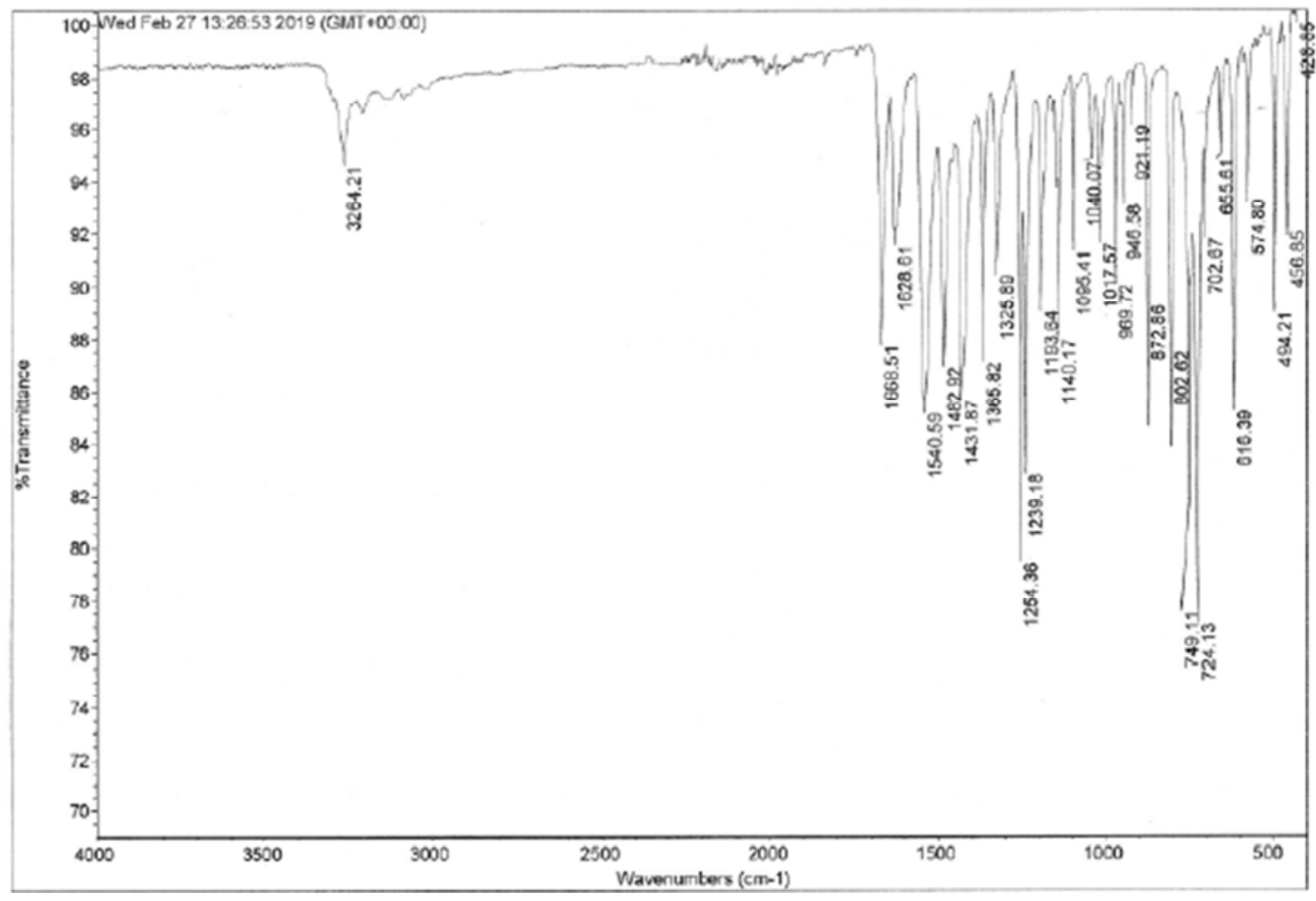

Figure 15. IR spectrum of $N$-(2,5-difluorophenyl) acetamide synthesized compound.

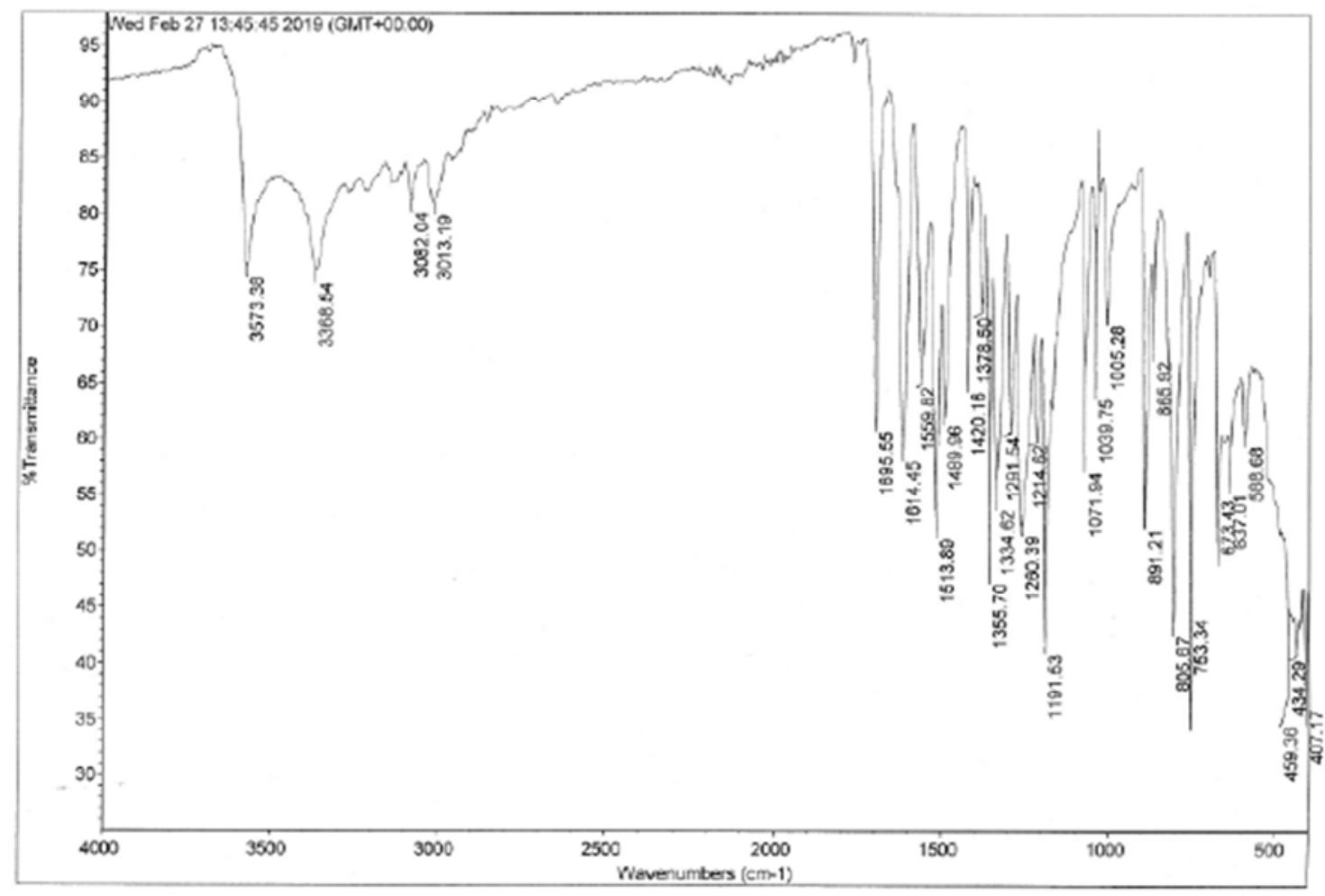

Figure 16. IR spectrum of N-(2,5-difluoro-4-nitrophenyl) acetamide synthesized compound. 
Table 13. IR ranges and corresponding functional groups [18].

\begin{tabular}{ll}
\hline Wavelength $\left(\mathbf{c m}^{-1}\right)$ & Corresponding Functional Group \\
\hline $1000-1400$ & $\mathrm{CF}$ \\
$1340-1390$ & $\mathrm{NO} 2$ \\
$1540-1570$ & $\mathrm{C}=\mathrm{O}$ \\
$1705-1725$ & $\mathrm{NH}$ \\
$3300-3500$ & $\mathrm{C}-\mathrm{O}-\mathrm{C}$ \\
$1250-1050$ & \\
\hline
\end{tabular}

Table 14. IR data for compounds synthesized.

\begin{tabular}{ll}
\hline Compound Name & Functional groups Observed in IR \\
\hline$N$-(2,5-difluorophenyl)acetamide & $\mathrm{CF}, \mathrm{C}=\mathrm{O}, \mathrm{NH}$ \\
$N$-(2,5-difluoro-4-nitrophenyl)acetamide & $\mathrm{CF}, \mathrm{C}=\mathrm{O}, \mathrm{NH}, \mathrm{NO} 2$ \\
1,4-difluoro-2,5-dinitrobenzene & $\mathrm{CF}, \mathrm{NO} 2$ \\
4-(2,5-dinitro-4-pyrrolid-1-yl)morpholine & $\mathrm{NO} 2$ \\
1,1 '-(2,5-dinitrobenzene-1,4-diyl)dipyrrolidine & $\mathrm{NO} 2, \mathrm{C}-\mathrm{O}-\mathrm{C}$ \\
\hline
\end{tabular}

\section{Conclusion and Future Work}

In conclusion, the desired product, 4-(2,5-dinitro-4pyrrolid-1-yl)morpholine has been successfully synthesized and purified. TLC of the final column showed the product is still present in the mixture and required further separation; therefore, another column is necessary for separation in order to increase its yield. In addition, other products including dipyrrolodine and di-morpholine substitution on the aromatic rings have been synthesized via the same synthetic route. This signifies the reaction produced a variety of compounds which are all precursors for different imidazo[5,4$f$ benzimidazole(imino)quinones.

In order to increase the yield of the desired compound, and increase the likelihood of morpholine and pyrrolidine substitution on to the aromatic ring, it can be recommended to add morpholine using a needle dropwise. Carrying out analytical techniques such as TLC or NMR at each interval would be required to check for the presence of morpholine as well as an unsubstituted C-F. Once it can be identified that morpholine had been substituted onto the ring, and a C-F is present, pyrrolidine can be added to allow for its substitution.

The next step in the reaction would be the reduction of 4(2,5-dinitro-4-pyrrolid-1-yl)morpholine, followed by oxidative cyclisation, nitration, reduction, and with the use of Fremy's salt the iminoquinone will be achieved as shown below (Figures $17 \& 18$ ). It is also recommended for 1,1'(2,5-dinitrobenzene-1,4-diyl)dipyrrolidine compound to undergo purification to remove impurities shown in the spectra. 4,4'-(2,5-dinitrobenzene-1,4-diyl)dimorpholine is required to be separated from the mixture by column chromatography, and analytical techniques are to be run to confirm the identity of the additional products. Future work would also include the novel imidazo[5,4$f$ benzimidazole(imino)quinones and their quinone derivatives to undergo screening at the NCI to assess which cancer cell line they are effective against, as well as undergo COMPARE analysis to compare their cytotoxicity profile against compounds in the database to receive a Pearson correlation value.

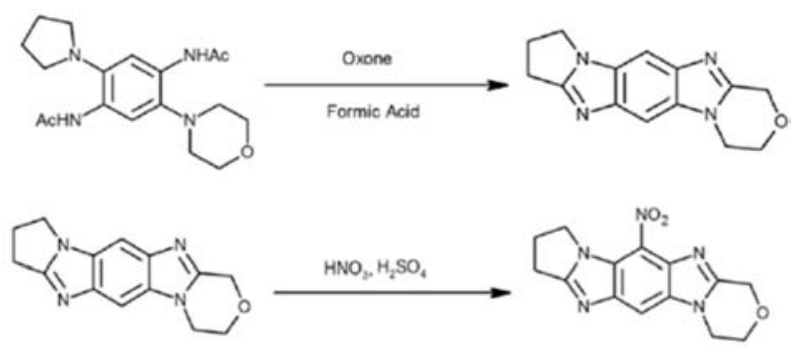

Figure 17. Oxidative cyclisation of diacetamide and nitration.

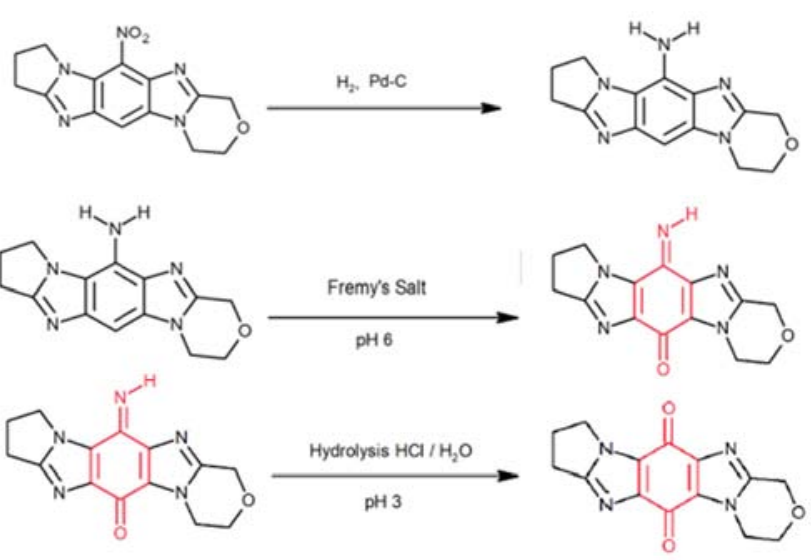

Figure 18. Synthesis of target iminoquinone.

\section{References}

[1] Eaton L., World Cancer Rates Set to Double, 2020. BMJ, 2003; 326 (7392): 728.

[2] Arruebo M, Vilaboa N, Sáez-Gutierrez B, et al. Assessment of the Evolution of Cancer Treatment Therapies, Cancers, 2011; 3 (3): 3279-330.

[3] Cooper G. M., The Cell: A Molecular Approach. $2^{\text {nd }}$ Edition. Sunderland (MA): Sinauer Associates; 2000.

[4] Paz M. M., Zhang X, Lu J, Holmgren A. A New Mechanism of Action for the Anticancer Drug Mitomycin C: MechanismBased Inhibition of Thioredoxin Reductase. Chem. Res. Toxicol, 2012; 25 (7), 1502-1511. 
[5] Siegel D, Yan C, Ross D., NAD(P)H: quinone oxidoreductase 1 (NQO1) in the sensitivity and resistance to antitumor quinones. Biochem Pharmacol, 2011; 83 (8): 1033-1040.

[6] Oh E. T., Park H. J., Implications of NQO1 in cancer therapy. BMB Rep. 2015; 48 (11): 609-617.

[7] Yang Y., Zhang Y., Wu Q., et al. Clinical Implications of High NQO1 expression in breast cancers. J. Exp. Clin. Cancer Res. 2014; 33 (1): 14.

[8] Li R., Bianchet M., et al. The three-dimensional structure of $\mathrm{NAD}(\mathrm{P}) \mathrm{H}$ : quinone reductase, a flavoprotein involved in cancer chemoprotection and chemotherapy: Mechanism of the two-electron reduction. Proc. Natl. Acad. Sci. USA, 1995; 92 (19): 8846-8850.

[9] Blaza J. N., Bridges H. R., et al. The mechanism of catalysis by type-II NADH: quinone oxidoreductases. Sci Rep., 2017; 7: 40165.

[10] Fagan V., Aldabbagh F., et al. COMPARE Analysis of the Toxicity of an Iminoquinone Derivative of the imidazo[5,4$f$ benzimidazoles with $\mathrm{NAD}(\mathrm{P}) \mathrm{H}$ : quinone oxidoreductase 1 (NQO1) activity and computational docking of quinones as NQO1 substrates. Bioorg. Med. Chem., 2012; 20 (10): 32233232 .

[11] Monga M., Sausville E. A., Developmental Therapeutics Program at the NCI: molecular target and drug discovery process. Leukemia, 2002; 16: 520-526.

[12] Sliwoski G., Kothiwale S., et al. Computational methods in drug discovery. Pharmacol Rev., 2014; 66 (1): 334-395.
[13] Clayden J., Warren S. G., Greeves N., Organic Chemistry, $2^{\text {nd }}$ edition. Oxford; Oxford University Press Inc., 2012.

[14] Madan R. L., Organic Chemistry, New Delhi; Tata McGraw Hill, 2013.

[15] Theophanides T., Introduction to Infrared Spectroscopy, Infrared Spectroscopy - Materials Science, Engineering and Technology, Intech Open; Greece; 2012.

[16] Coskun O., Separation techniques: Chromatography. North Clin Istanb., 2016; 3 (2): 156-160.

[17] William R. Dolbier Gouverneur, Véronique. Guide to Fluorine NMR for Organic Chemistry Angewandte Chem. International Edition, 2010 49: 4335.

[18] Williams D, Flemming I. Spectroscopic Methods in Organic Chemistry, Sixth Edition, New York: McGraw-Hill Education; 2008, p. 163.

[19] Traynelis, V. J., et al. J. Org. Chem., 1964, vol. 29, p. 123.

[20] Timofeev; Bazanov; Zubritskaya, Russian Journal of Organic Chemistry, 2016; 52 (12): 1756-1761.

[21] Swarts Recaeil des Travaux Chimiques des Pays-Bas, 1914, vol. 33, p. 299.

[22] Finger et al.J. Am. Chem. Soc., 1959, vol. 81, p. 94.

[23] Bradley, G. W., Morris, D. G., J. Chem. Res. Synop. 1993, p. 220.

[24] Cadogan et al. Journal of the Chemical Society, 1966, p. 933. 